\section{Cross species applicability of psychiatric diagnosis and treatment}

\section{Linda R Montague}

Glanrhyd Hospital, Bridgend, Mid Glamorgan Linda R Montague, MRCPSYCH, senior registrar in psychiatry

Br Med f 1989;299:1569
The diagnostic problems caused by depressive pseudodementia are well recognised in humans. Little consideration, however, has been given to the possibility that such a syndrome may occur in other species. I report a case of depressive pseudodementia in a domestic cat.

\section{Case report}

The patient was a female tortoiseshell and white cat of unknown age but judged by experienced observers to be between 12 and 15 . She came to the notice of the medical profession after the death of her 89 year old owner, being discovered living in conditions of squalor by the owner's general practitioner. There was clear evidence of self neglect as her fur was matted with filth and complete loss of previous house training skills was apparent. Both ears were infected and discharging. The general practitioner obtained custody of the cat and sought the advice of a veterinary practitioner, who successfully treated the ear infection. She remained withdrawn and self neglecting; washing behaviour was rarely observed, house training could not be reestablished, and she spent most of her time crouched in a corner in the utility room of the doctor's home. Later she left the house and was found in a disused outside toilet, where she remained for some time, refusing food and water that were put down for her. The doctor thought that senile dementia was the likely diagnosis and that euthanasia was the only humane option.

The case came to my attention, and I thought that diagnostic and treatment options had not been exhausted and took the cat into my care for an intensive rehabilitation programme. The daily programme devised included intensive stroking and lengthy periods of being held on my lap; brushing of matted fur to encourage washing behaviour; small tempting meals and ample quantities of milk; occupational therapy with a catnip mouse and a length of string; and a regular toiletting programme. Contact with other cats resident in my household provided role models and further stimulation.

The response to treatment was dramatic. One month after commencing the programme she was alert, sociable, and active. Her fur was clean and washing

\section{Ear pain referred by the vagus}

\section{J N Blau}

National Hospitals for Nervous Diseases, Queen Square, London WCIN 3BG neurologist
J N Blau, MD, consultant

BrMed f 1989;299:1569-70
This case report indicates that pain may be referred from a hiatus hernia to one ear and spread to the first division of the trigeminal nerve on the same side.

\section{Case report}

An 82 year old proprietor of an old peoples' home complained of recurrent painful episodes in the right ear that he had experienced for the past three to four years. Initially occurring at irregular intervals, the pain had become more frequent during the previous six months, occurring each morning between 9 and

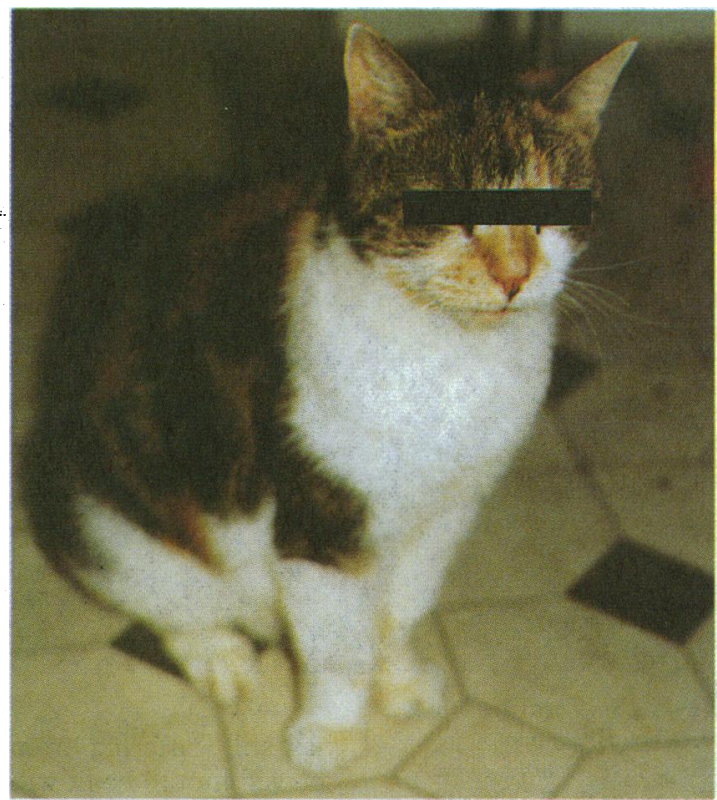

Patient after intensive rehabilitation programme

behaviour was often observed. Difficulty remained in establishing house training because of episodic diarrhoea, but this was found to be secondary to overindulgence in milk drinking, and a rationing scheme successfully overcame the problem. She subsequently succeeded in establishing a dominant position in the household cat hierarchy and showed herself capable of learning new skills by mastering the use of the catflap.

\section{Comment}

The apparent intractability of the cat's condition initially led to a diagnosis of dementia, but the response to intensive treatment showed a reversible condition. The preceding neglect by her dying owner and the subsequent bereavement may have been the precipitants of a reactive depression presenting as psuedodementia. As in elderly humans, social stimulation and encouragement of self care skills were important in restoring normal functioning. The maintenance of continence by regular toiletting and avoidance of bowel disturbance also parallels the treatment of elderly human patients.

This case emphasises the importance of considering treatable causes in apparently demented patients, both human and feline, and also indicates that principles of rehabilitative treatment are applicable beyond the human species.
$930 \mathrm{am}$, recurring variably later in the day and more so during the evening. The pain, a severe deep seated ache, was felt inside his right ear (he pointed to the external auditory meatus with his index finger) radiating upwards and forward over the right parietal region to the right temple. He had tried various analgesics, deriving some benefit, but he had gained complete relief about 30 minutes after taking antacids, magnesium trisilicate, or a proprietary preparation containing light magnesium carbonate. His wife, who accompanied him, said that two doctors had curtly dismissed the idea that antacids could relieve headache.

His history showed that a barium meal examination had identified a hiatus hernia, and at times he regurgitated a bitter tasting fluid into his mouth. Recently he had had two episodes conforming to transient global amnesia provoked by swimming. In the more distant past he had had renal calculi and a prostatectomy and 


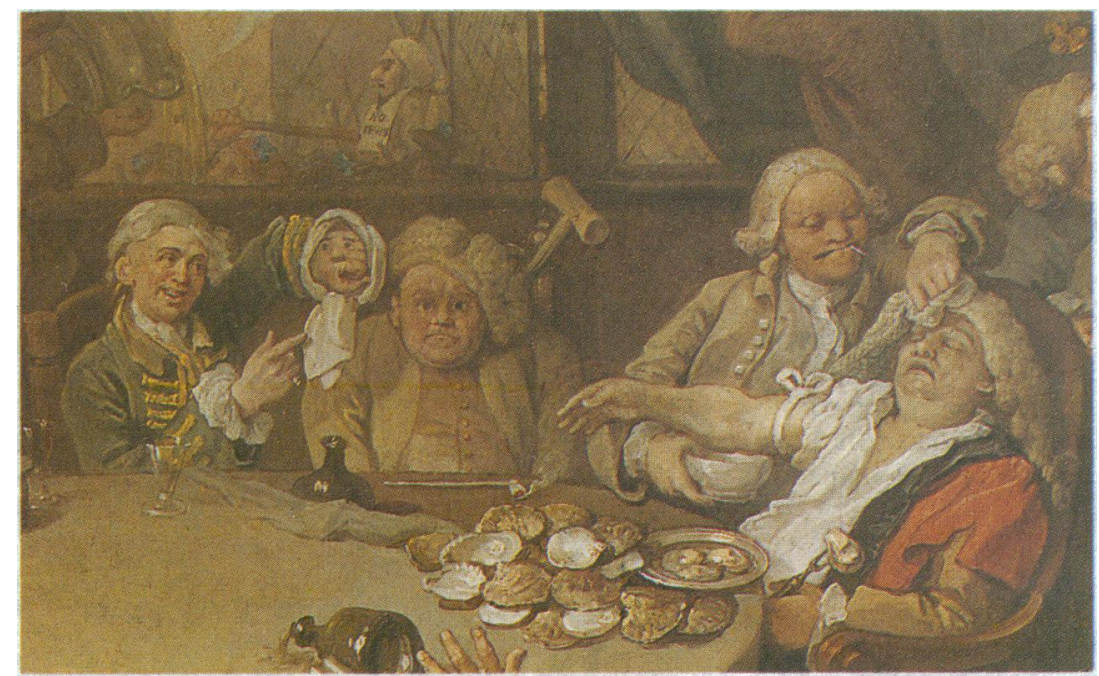

Detail from The Election 1. An Election Entertainment by Hogarth.'By courtesy of the Trustees of Sir Fohn Soane's Museum was still suffering from diverticulitis. Examination showed him to be fit without abnormal physical signs in the nervous or general medical systems. He had no abnormalities in or around the right ear. His blood pressure was 135/85 and his urine free of protein and sugar.

I explained to the patient and his wife that I had not encountered this before but wondered whether the pain arose from the vagus and was referred by Arnold's nerve (explained in lay terms). I also told him about the Alderman's trick of touching the back of the pinna with a cold damp napkin to promote gastric peristalsis. ${ }^{12}$ More practically, I advised taking antacids prophylactically immediately after breakfast, which he ate at $830 \mathrm{am}$, and after his evening meal. Follow up 10 months later by telephone (he failed to keep a two month follow up appointment) showed that he had sought a further opinion and had been taking ranitidine $300 \mathrm{mg}$ night and morning initially and had recently reduced the dose, taking one tablet only in the evenings. He had had no further pain in his right ear or head.

\section{Comment}

This case supports the hypothesis that unilateral facial pain may be referred by the vagus. Bindoff and Heseltine recorded eight patients in whom a lung carcinoma provoked unilateral facial pain predominantly in the jaw $^{3}$; in five of the eight they specifically mentioned pain in the ear on the same side. My patient supports their view but shows that the cause may be benign.

Pain in the ear or pressure across the bridge of the nose are "heart sinkers" because usually there is no cause to be found and we are bereft of ideas on pathogenesis or treatment. This case report, however, shows that aural pain, albeit rarely, may arise from a hiatus hernia. Perhaps gastroenterologists have encountered this picture or might look out for this syndrome in the future.

1 Treves F. Surgical applied anatomy. 8th ed. London: Cassel, 1926:97. 2 MacNalty A. British medical dictionary. London: Caxton, 1961;964.

3 Bindoff LA, Heseltine D. Unilateral facial pain in patients with lung cancer: a referred pain via the vagus? Lancet 1988; ;:812-5.

\section{$e_{1}^{2}$ \\ $\gamma$ Eyelid abscess in an egg nog drinker//}

\section{H S/Markus, AWolverson}

Department of Medicine, University Hospital, Queen's Medical Centre, Nottingham]NG7 2UH H S Markus, MRCP, medical registrar

A Wolverson, BM, house physician

Correspondence to: $\mathrm{Dr}$ Markus.

BrMed F 1989;299:1570-1 upper eyelid abscess in an egg nog drinker.
A substantial increase in salmonella infections has been reported recently; this has been partly accounted for by an increase in infection with Salmonella enteritidis phage type 4 , transmission of which has been associated with eggs. Unlike $S$ typhi and $S$ paratyphi type A, for which rates of bacteraemia of $63 \%$ and $71 \%$ respectively have been reported, $S$ enteritidis is thought to be less invasive, with a bacteraemic rate of only $1 \% .^{\prime}$ Correspondingly, extraintestinal salmonellosis has been less commonly reported with $S$ enteritidis. We report a recent case of $S$ enteritidis infection presenting with an

\section{Case report}

A 72 year old West Indian, resident in England since 1950 , presented to the ophthalmology department with a large abscess of the left upper eyelid that developed over two weeks. He gave no recent history of gastrointestinal symptoms. The abscess was drained under general anaesthetic; it extended to the periosteum of the frontal bone, though the periosteum itself seemed intact. He was treated with flucloxacillin and fusidic acid, The next day culture of the pus grew $S$ enteritidis (identified as phage type 4) sensitive to ampicillin, cephalosporins, and gentamicin. The antibiotics were changed to intravenous cefotaxime. He still had a fever $\left(39.5^{\circ} \mathrm{C}\right)$, and a technetium isotope scan showed extensive uptake in the left frontal bone extending well above the supraorbital ridge (figure). Computed tomography showed a $2 \mathrm{~cm}$ lytic lesion in the left frontal bone above the left superior orbital ridge. Surgical exploration confirmed frontal osteomyelitis, and the cavity was drained; bilateral maxillary antral washouts were also performed. The next day his temperature was normal, and he made a good recovery, with three weeks of intravenous and then three weeks of oral cephalosporin. Electrophoresis of haemoglobin yielded normal results.

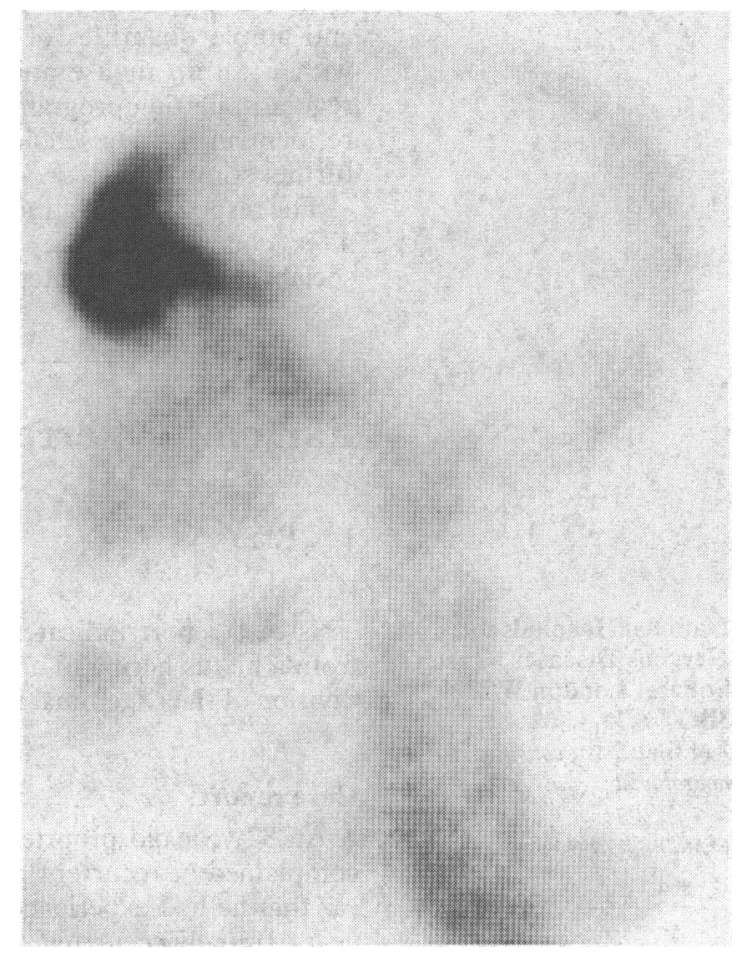

Technetium bone scan showing increased uptake in periorbital region and frontal bone 